\title{
Effects of titanium oxide nanoparticles on Oryzias latipes embryos and sac-fry under different irradiation conditions
}

\author{
Sun-Hwa Nam, Yu-Jin Shin, Youn-Joo $\mathrm{An}^{\dagger}$ \\ Department of Environmental Health Science, Konkuk University, 120 Neungdong-ro, Gwangjin-gu, Seoul 05029, Republic of Korea
}

\begin{abstract}
Some phototoxicity of titanium dioxide nanoparticles $\left(\mathrm{TiO}_{2} \mathrm{NPs}\right)$ has been reported in recent years in studies with fish embryos or larvae. However, it is necessary to focus on the potential effects of embryonic exposure due to irreversible abnormalities and mortalities observed in sac-fry, and to expand various fish embryos to generate multiple test species. The aim of this study was to evaluate the effects of $\mathrm{TiO}_{2}$ NPs under different irradiation conditions in exposed Oryzias latipes (O. latipes) at the embryonic and sac-fry stages. The effects of different irradiation conditions were observed using ultra-violet (UV) and visible light, and the corresponding effects were monitored by determining cumulative mortality and abnormality. O. latipes were exposed for 8 d to $0,1,5,10$, or $50 \mathrm{mg} / \mathrm{L} \mathrm{TiO}_{2} \mathrm{NPs}$ under UV $\left(4,818.86 \mathrm{~mW} / \mathrm{m}^{2}\right.$ at the bottom of clear vials) or visible light, after which the embryos were transferred to NP-free embryo-rearing solution until 16 days post fertilization (dpf). Abnormalities of embryos and sac-fry increased at high $\mathrm{TiO}_{2} \mathrm{NP}$ concentrations under UV irradiation, compared to control samples treated with visible light or UV irradiation alone. This work provides information regarding the phototoxicity of $\mathrm{TiO}_{2} \mathrm{NPs}_{\mathrm{s}}$ using $\mathrm{O}$. latipes at the embryonic and sac-fry stages.
\end{abstract}

Keywords: Fish embryo, Oryzias latipes, Phototoxicity, $\mathrm{TiO}_{2} \mathrm{NPs}$, UV irradiation

\section{Introduction}

Titanium dioxide nanoparticles $\left(\mathrm{TiO}_{2} \mathrm{NPs}\right)$ have been used in beauty products, hygienic goods, and textiles [1-3]. Boxall et al. [2] presented modeling data used to estimate the $\mathrm{TiO}_{2} \mathrm{NP}$ concentration in water as $0.245 \mathrm{mg} / \mathrm{L}$, based on a $100 \%$ market-penetration scenario of paints and sunscreen, particularly paints containing $5 \mathrm{mg} / \mathrm{g} \mathrm{\textrm {TiO } _ { 2 }} \mathrm{NPs}$ and sunscreen containing $50 \mathrm{mg} / \mathrm{g} \mathrm{\textrm {TiO } _ { 2 }} \mathrm{NPs}$. $\mathrm{TiO}_{2} \mathrm{NPs}$ tend to become rapidly distributed throughout the environment because of their small sizes and non-biodegradability [3], and the potential exposure to bio-receptors increases as a consequence.

Several studies have been conducted in recent years to assess the toxicity of $\mathrm{TiO}_{2} \mathrm{NPs}$. Because the photoreactivity of $\mathrm{TiO}_{2} \mathrm{NPs}$ can cause differing toxicities based on the bio-receptors that are activated [1, 4-5], the phototoxicities of $\mathrm{TiO}_{2} \mathrm{NPs}$ have been tested in various organisms, including fish [1, 4, 6-11], waterfleas [7, 9], algae [12], and bacteria [13]. The phototoxicity of $\mathrm{TiO}_{2} \mathrm{NPs}$ induced increased mortality of Daphnia magna [7, 9] and decreased colony formation of Escherichia coli and Bacillus subtilis [13].
Evidence suggests that $\mathrm{TiO}_{2} \mathrm{NPs}$ in surface water can readily absorb ultra-violet (UV) irradiation and that the absorbed energy can generate an excited state by electron-hole pair production on the surface of particles [4, 7, 8, 12].

Some authors have reported the phototoxicity of $\mathrm{TiO}_{2} \mathrm{NPs}$ using fish embryos or larvae [1, 4, 6-7, 11]. These studies were focused on the effects of Danio rerio (D. rerio) embryos $[1,4,11,14]$ and larvae [11, 14], Oryzias latipes (O. latipes) larvae [7, 9], and Piaractus mesopotamicus juveniles [6]. Although Ma et al. [14] presented evidence to suggest that yolk-sac larvae were most sensitive to the phototoxicity of $\mathrm{TiO}_{2} \mathrm{NPs}$, it is still necessary to study their effects on potential embryonic exposure due to irreversible abnormalities and mortalities observed in sac-fry [15-16]. However, limited phototoxicity data exist regarding the effects of $\mathrm{TiO}_{2} \mathrm{NPs}$ on fish embryos, and such studies have mainly focused on $D$. rerio. Therefore, it is necessary to expand various fish embryos for use as multiple test species in order to assess the phototoxicity of $\mathrm{TiO}_{2}$ NPs in water. O. latipes is recommended as a test fish species by Organization for Economic Co-operation and Development (OECD) No. 212 [17].
This is an Open Access article distributed under the terms of the Creative Commons Attribution Non-Commercial License (http://creativecommons.org/licenses/by-nc/3.0/) which permits unrestricted non-commercial use, distribution, and reproduction in any medium, provided the original work is properly cited.

Copyright (C) 2017 Korean Society of Environmental Engineers
Received May 4, 2017 Accepted June 18, 2017

${ }^{\dagger}$ Corresponding author

Email: anyjoo@konkuk.ac.kr

Tel: +82-2-2049-6090 Fax: +82-2-2201-6295

ORCID: 0000-0002-0193-1929 
The aim of this study was to evaluate the effects of $\mathrm{TiO}_{2} \mathrm{NPs}$ under different irradiation conditions in exposed $O$. latipes at the embryonic and sac-fry stages. The effects of different irradiation levels were observed using UV and visible light, and the corresponding effects were monitored by measuring cumulative mortality and abnormality. O. latipes was chosen as the test species due to the lack of available phototoxicity data. To the best of our knowledge, this is the first study to evaluate phototoxicity of $\mathrm{TiO}_{2}$ NPs using $O$. latipes embryos.

\section{Materials and Methods}

\subsection{Characterization and Preparation of Nanoparticles}

$\mathrm{TiO}_{2}$ NPs (particle size $21 \mathrm{~nm}, \mathrm{P} 25$, white powder form) were purchased from Evonik Degussa (Germany). A field emission transmission electron microscope (FE-TEM, JEM2200FS, JEOL, Japan) was used to observe the morphology of the NPs. Specific surface area of the $\mathrm{TiO}_{2}$ NPs was analyzed by particle size analyzer (UPA-150, Microtrac, USA). An electrophoretic light scattering spectrophotometer (ELS-8000, Otuska Electronics Co., Japan) was used to measure particle size distributions of hydrodynamic diameters and zeta potential of $10 \mathrm{mg} / \mathrm{L} \mathrm{TiO}_{2} \mathrm{NPs}$ dispersed in deionized water (DW) and embryonic rearing solution (ERS). UV absorption spectra of $10 \mathrm{mg} / \mathrm{L} \mathrm{TiO}_{2}$ NPs suspended in ERS was measured by a UV/Vis spectrophotometer (Libra S32 PC, Biochrom Ltd., Cambridge, UK) at 10-min intervals for $1 \mathrm{~h}$, to verify aggregation of $\mathrm{TiO}_{2}$ NPs. ERS included NaCl (1 g/L), KCl (0.03 g/L), $\mathrm{CaCl}_{2} \cdot 2 \mathrm{H}_{2} \mathrm{O}$ (0.04 g/L), $\mathrm{MgSO}_{4} \cdot 7 \mathrm{H}_{2} \mathrm{O}(0.163 \mathrm{~g} / \mathrm{L})$, and methylene blue $(1.0 \mathrm{mg} / \mathrm{L})$ to prevent fungal growth [18]. When UV spectra analysis, Methylene blue was eliminated from the ERS due to photodegradation [18]. A stock solution of $100 \mathrm{mg} / \mathrm{L} \mathrm{TiO}_{2} \mathrm{NPs}$ was prepared by dispersing the NPs in ERS with sonication for $10 \mathrm{~min}$ in a water bath sonicator (40 kHz frequency, Powersonic 420, Hwashin Technology, Korea). A series of exposure concentrations of $\mathrm{TiO}_{2}$ NPs $(0,1,5,10$, and $50 \mathrm{mg} / \mathrm{L})$ were diluted with ERS.

\subsection{Test Species and Pre-culture Conditions}

O. latipes (Japanese medaka) was received from the National Academy of Agricultural Science (NAAS, Suwon, Korea). Adult orange-red type $O$. latipes for broodstock were kept in dechlorinated tap water $\left(\mathrm{pH} 7.0 \pm 0.2\right.$; temp. $25 \pm 2^{\circ} \mathrm{C}$; light:dark $\left.=16: 8 \mathrm{~h}\right)$, with a diet of commercial Tetra Min (Tetra Werke, Germany) and brine shrimp (OSI PRO80TM, USA) twice per day. On the day of the experiment, newly fertilized and healthy eggs of $O$. latipes were collected from the broodstock.

\subsection{Phototoxicity Assay Using Fish Embryo and Sac-fry}

The fish embryo and sac-fry assay was performed based on the OECD guidelines (No. 212) for chemical testing [10, 14, 15, 19]. Embryos (9-10 stages) were transferred into $2 \mathrm{~mL}$ clear vials with screw caps (Wheaton), one embryo per vial and one $\mathrm{mL}$ exposure solution per vial, and there were 10-15 replicates prepared. All experiments were repeated 1 to 4 times for treatments and 3 to 4 times for controls. The capped vials were placed upside down in a photoreactor (model LZC-4, Luzchem Research Inc., Ottawa, ON, Canada) under a UV lamp for UV irradiation and in the laboratory under standard fluorescent lamps for visible light irradiation, before hatching. The photoreactor has one UV lamp (spectral distribution of $316 \mathrm{~nm}$ to $400 \mathrm{~nm}$ ), positioned $18 \mathrm{~cm}$ above the test units. The light intensity was measured by a spectroradiometer (SPR 4001, Luzchem Research Inc., Ottawa, ON, Canada) and its values were $6,198.03 \mathrm{~mW} / \mathrm{m}^{2}$ at the top of the clear vials and $4,818.86 \mathrm{~mW} / \mathrm{m}^{2}$ at the bottom of the clear vials. At 8 days post fertilization ( $8 \mathrm{dpf}$, when the control embryos hatched), exposure solutions were changed with NP-free embryo-rearing solution. UV irradiated- or visible light irradiated-vials were maintained in the incubator under pre-culture conditions (without oxygen and food supply in both the control and exposure groups). Fish embryos and sac-fry were observed daily under a dissection microscope based on cumulative mortality and various abnormalities; abnormal embryos and sac-fry: Heart damage (e.g., tube heart, blood circulation disorder, pericardial necrosis, pericardial edema, and hemostasis), whole body necrosis, malformation of the pericardium and peritoneum, gallbladder edema, small eyes, tail deformity, swim bladder deformity (e.g., undeveloped, over-inflated, and deflated swim bladder), and erratic swimming activity. The dead embryos or sac-fry were immediately eliminated from the test units. The detailed experimental design of fish embryo and sac-fry assay is shown in Fig. 1. The effect of Ti ions was not measured because $\mathrm{TiO}_{2}$ NPs are insoluble in water [3].

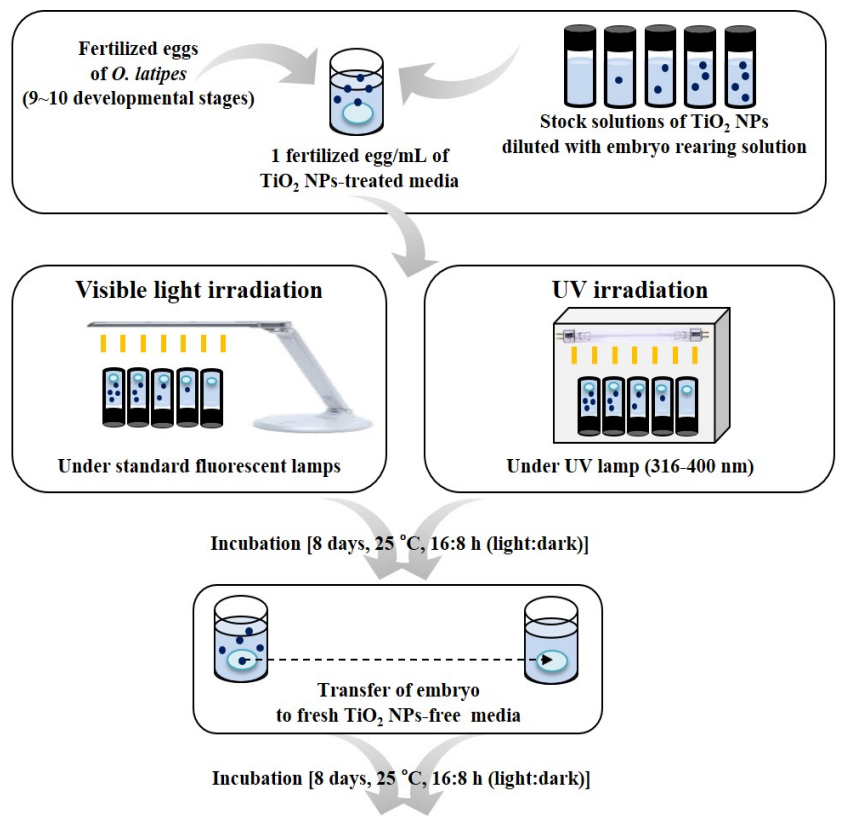

Observation of cumulative mortality and abnormality of embryos/sac-fry

Fig. 1. Experimental study design. Fertilized eggs of Oryzias latipes were exposed to $\mathrm{TiO}_{2}$ NPs in embryo rearing solution until 8 days post fertilization $(\mathrm{dpf})$, under visible light or UV irradiation. At $8 \mathrm{dpf}$, the exposure solution was replaced with TiO2 NP-free embryo rearing solution. All tests were assessed with respect to cumulative mortality and abnormalities of embryos and sac-fry until $16 \mathrm{dpf}$ (modified from Shin et al. [10, 15]). 


\subsection{Statistical Analysis}

The results were reported as the sum of cumulative mortalities and abnormalities of embryos and sac-fry. If abnormal embryo was counted, sac-fry developed from an abnormal embryo was excluded from the calculation (even if the abnormal sac-fry manifested). The data were presented as mean \pm standard error. Means were compared using one-way analysis of variance (ANOVA) (Origin 8, OriginLab Corp.). Multiple comparisons were conducted using Fisher test and differences were considered statistically significant at $p<0.05$.

\section{Results and Discussion}

\subsection{Physicochemical Characterization and Dissolution of $\mathrm{TiO}_{2} \mathrm{NPs}$}

Fig. 2 shows physicochemical characterization of $\mathrm{TiO}_{2} \mathrm{NPs}$. Morphological TEM image of $\mathrm{TiO}_{2}$ NPs is shown in Fig. 2(a). Fig. 2(b) shows distributions of the hydrodynamic diameter of $\mathrm{TiO}_{2}$ NPs suspended in DW and ERS. According to Table 1, mean hydrodynamic diameter of $\mathrm{TiO}_{2} \mathrm{NPs}$ dispersed in ERS was estimated to be $1,218 \pm 109 \mathrm{~nm}$, which is 3.4 -fold greater than the $\mathrm{TiO}_{2}$ NPs dispersed in DW (354 $\pm 15 \mathrm{~nm})$. The zeta potential of $\mathrm{TiO}_{2}$ NPs was estimated to be $-7.0 \pm 2.4 \mathrm{mV}$ (in ERS) and $-2.0 \pm 1.4$ $\mathrm{mV}$ (in DW). This indicates that $\mathrm{TiO}_{2} \mathrm{NPs}$ are rapidly coagulated or flocculated in solution. The specific surface area of $\mathrm{TiO}_{2} \mathrm{NPs}$ analyzed using the Brunauer-Emmett-Teller (BET) method was estimated to be $55 \pm 0.4 \mathrm{~m}^{2} / \mathrm{g}$. The UV absorption spectra of 10 $\mathrm{mg} / \mathrm{L} \mathrm{TiO}_{2} \mathrm{NPs}$ suspended in ERS were determined at 10-min intervals for $1 \mathrm{~h}$ (Fig. 2(c)). $\mathrm{TiO}_{2}$ NPs absorbed UVA light (320-400 $\mathrm{nm}$ ) and peaked at $330-340 \mathrm{~nm}$ for $\mathrm{TiO}_{2}$ NPs. The absorbance

Table 1. Glossary of Terms and Equations Used to Analyze Chlorophyll Fluorescence Transients

\begin{tabular}{ll}
\hline \multicolumn{1}{c}{ Properties } & \multicolumn{1}{c}{ TiO $_{2}$ NPs } \\
\hline Manufacturer $_{\text {Crystal structure }^{\mathrm{a}}}$ & $\begin{array}{l}\text { Evonik Degussa } \\
\text { Anatase 72.6\%, Rutile } \\
\text { Surface coating }\end{array}$ \\
${\text { Mean hydrodynamic diameter }(\mathrm{nm})^{\mathrm{b}}}^{\mathrm{b}}$ & \\
\multicolumn{1}{c}{ Distilled water } & $354 \pm 15$ \\
\multicolumn{1}{c}{ Embryo rearing solution } & $1,218 \pm 109$ \\
Zeta potential (mV) & \\
\multicolumn{1}{c}{ Distilled water } & \\
\multicolumn{1}{c}{ Embryo rearing solution } & $-7.0 \pm 2.4 \pm 1.4$ \\
Specific surface water $\left(\mathrm{m}^{2} / \mathrm{g}\right)^{\mathrm{c}}$ & $55 \pm 0.4$ \\
\hline
\end{tabular}

\footnotetext{
a supplied from the manufacturer.

${ }^{\mathrm{b}}$ measured by electrophoretic light scattering spectrophotometer (ELS).

${ }^{\mathrm{c}}$ measured by particle size analyzer.
}
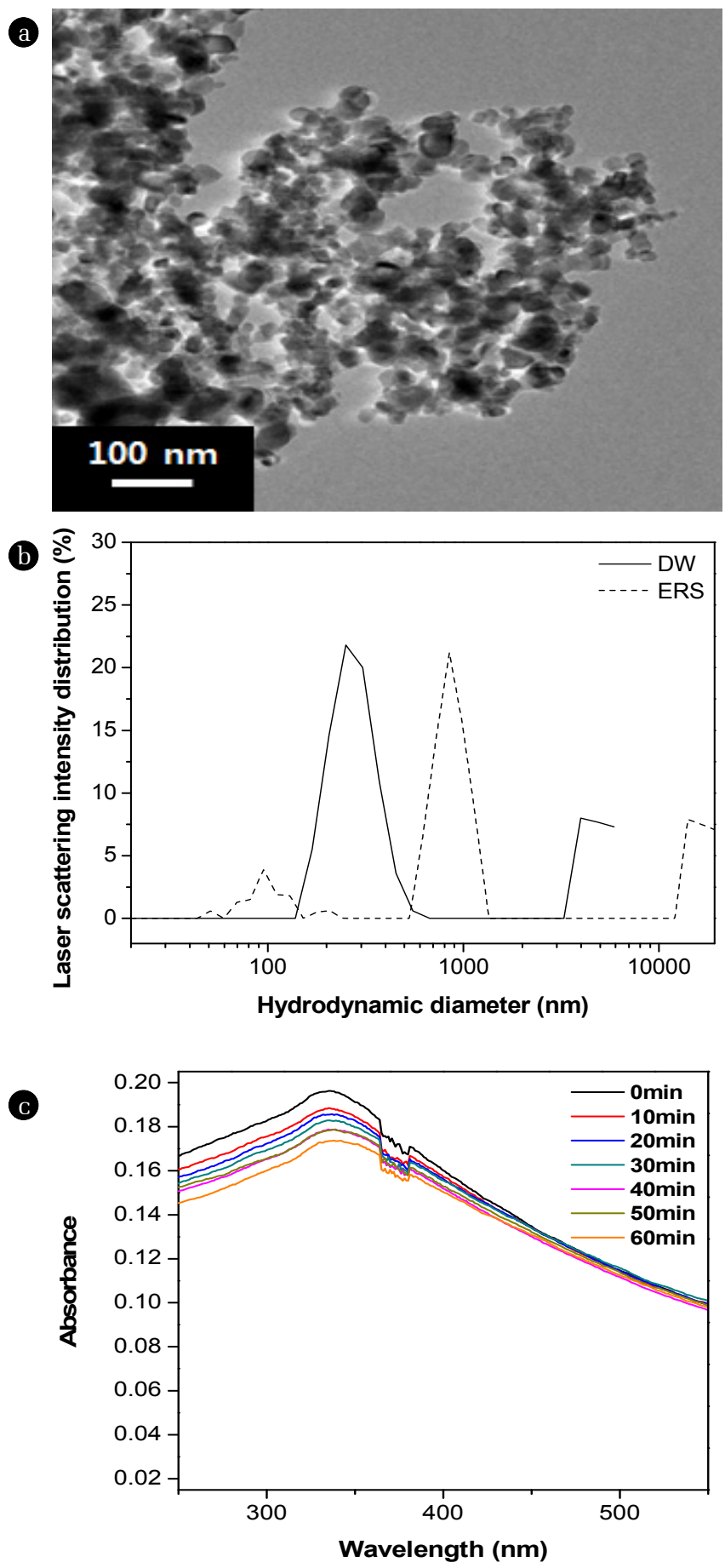

Fig. 2. Transmission electron microscope image (a), particle size distributions of hydrodynamic diameters (b), and absorption spectra (c) of $\mathrm{TiO}_{2} \mathrm{NPs}$.

of $\mathrm{TiO}_{2} \mathrm{NPs}$ decreased as a function of increased irradiation time. This is possibly due to aggregation of NPs. When $\mathrm{TiO}_{2} \mathrm{NPs}$ were re-sonicated for $10 \mathrm{~min}$, the absorbance of $\mathrm{TiO}_{2} \mathrm{NPs}$ increased (data not shown). In a previous study, Lee and An [12] reported the absorbance of $\mathrm{TiO}_{2} \mathrm{NPs}$ as a function of time until $1 \mathrm{~h}$. They 
reported the absorbance of $\mathrm{TiO}_{2}$ dispersed in OECD algal medium decreased as a function of increased irradiation time, similar to the results obtained in this study.

\subsection{Effects of $\mathrm{TiO}_{2} \mathrm{NPs}$ on the Embryos and Sac-fry of 0 . latipes}

Fig. 3-5 show embryos and sac-fry at $16 \mathrm{dpf}$ of exposure to $\mathrm{TiO}_{2}$ NPs, under either visible light or UV irradiation. The abnormalities of embryos and sac-fry were increased at 10 and $50 \mathrm{mg} / \mathrm{L} \mathrm{NPs}$ under UV irradiation, compared to the control under visible light irradiation or UV irradiation ( $p<0.05$ ) (Fig. 3). Under UV irradiation, compared to the control, at $50 \mathrm{mg} / \mathrm{L} \mathrm{TiO}_{2} \mathrm{NPs}$, some $\mathrm{TiO}_{2}$ NP-treated embryos developed but exhibited abnormalities $(p<$ 0.05). Tube heart, pericardial edema, and undeveloped or over-inflated swim bladder deformity were primarily induced as symptom of embryo and some exhibited hemostasis, malformation of pericardium, whole-body necrosis, pericardial edema, pericardial necrosis, and tail deformity (Fig. 4). In particular, the effect of $\mathrm{TiO}_{2}$ NPs during the embryonic stages of some fish $(10 \%$ for $1 \mathrm{mg} / \mathrm{L}$

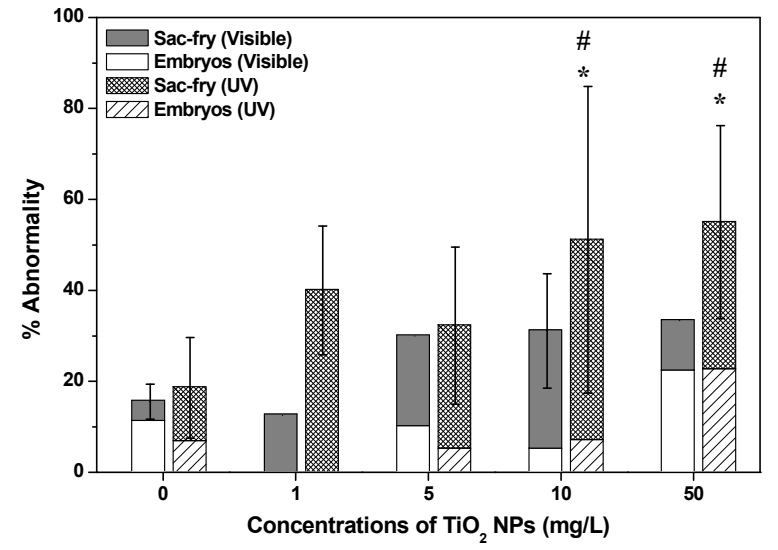

Fig. 3. Cumulative abnormality of $\mathrm{TiO}_{2} \mathrm{NPs}$ under visible light or UV irradiation on Oryzias latipes. Asterisks $(*)$ indicate significant differences from controls under visible light irradiation $(p<0.05)$. Crosshatches (\#) indicate significant differences from controls under UV light irradiation $(p<0.05)$. and $10 \%$ for $50 \mathrm{mg} / \mathrm{L}$ ) died as sac-fry, and embryonic exposure generated irreversible developmental impairment. Under visible light irradiation, some $\mathrm{TiO}_{2}$ NP-treated embryos developed but exhibited abnormalities [e.g., deflated yolk, undeveloped or over-inflated swim bladder deformity, blood circulation disorder at $50 \mathrm{mg} / \mathrm{L} \mathrm{TiO}_{2} \mathrm{NPs}$. The abnormalities shown by sac-fry included undeveloped or over-inflated swim bladder deformity and hemostasis. However, there was no significant increase of abnormality under visible light irradiation, compared to control $(p<$ 0.05). There was no significant difference of abnormality between UV and visible light at the same exposure concentrations in the range of tested exposure concentrations $(p<0.05)$. No significant mortality of $\mathrm{TiO}_{2}$ NP-treated sac-fry was observed under UV irradiation and visible light irradiation $(p<0.05)$ (Fig. 5).

\subsection{Comparison of $\mathrm{TiO}_{2} \mathrm{NPs}$ on the Embryos and Sac-fry of 0 . latipes under UV and Visible Light}

We studied the phototoxicity of $\mathrm{TiO}_{2} \mathrm{NPs}$ under UV and visible light using $O$. latipes embryos and sac-fry, and found that there are no significant differences at low exposure concentrations (0-50 $\mathrm{mg} / \mathrm{L}$ ). Likewise, Bar-Ilan et al. [4] studied the phototoxicity of anatase/rutile $\mathrm{TiO}_{2}$ NPs using zebrafish embryos. They reported that there are no significant differences in the survival of embryos under UV or visible light at $\mathrm{TiO}_{2} \mathrm{NP}$ concentrations of 0,1 , and $10 \mathrm{mg} / \mathrm{L}$. However, their significant differences of survival are observed at 100, 500, and 1,000 mg/L. Clemente et al. [1] studied the phototoxicity of anatase and anatase/rutile $\mathrm{TiO}_{2} \mathrm{NPs}$ using zebrafish eggs and larvae. They reported that there are no significant differences in the survival of eggs and larvae under UV or visible light at $\mathrm{TiO}_{2} \mathrm{NP}$ concentrations of 0,1 , and $10 \mathrm{mg} / \mathrm{L}$. However, their significant differences of survival are observed at $100 \mathrm{mg} / \mathrm{L}$. Meanwhile, Faria et al. [5] studied the phototoxicity of rutile and anatase/rutile $\mathrm{TiO}_{2}$ NPs using zebrafish embryos. They reported that rutile $\mathrm{TiO}_{2} \mathrm{NPs}$ did not cause significant mortality at a concentration of $1 \mathrm{mg} / \mathrm{mL}$ under solar radiation. However, anatase/rutile $\mathrm{TiO}_{2} \mathrm{NPs}$ caused significant mortality at the same concentration and radiation. Felix et al. [11] studied the phototoxicity of anatase/rutile and anatase poly (acrylic acid)-coated $\mathrm{TiO}_{2} \mathrm{NPs}$ using

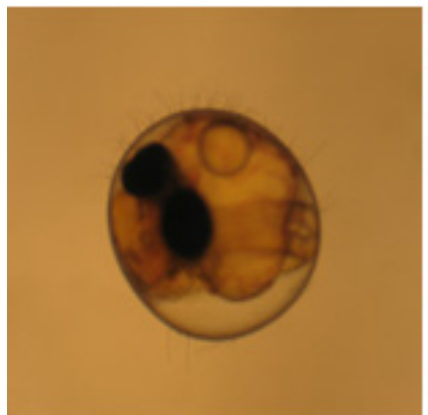

Healthy embryo

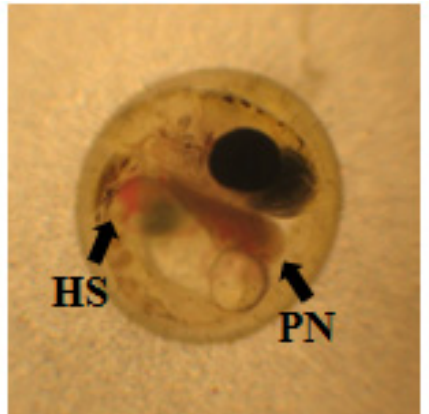

Abnormal embryo

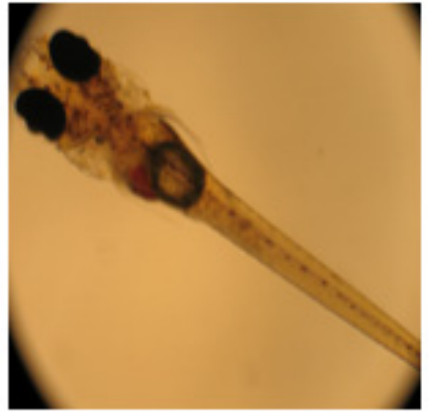

Healthy sac-fry

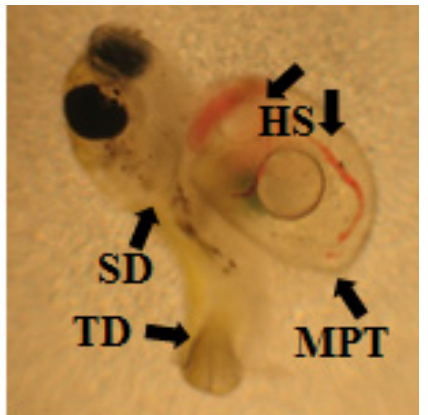

Abnormal sac-fry

Fig. 4. Morphological appearance of Oryzias latipes exposed to $\mathrm{TiO}_{2} \mathrm{NPs}$. HS: hemostasis, PN: pericardial necrosis, SD: swim bladder deformity, TD: tail deformity, and MPT: malformation of the pericardium and peritoneum. 


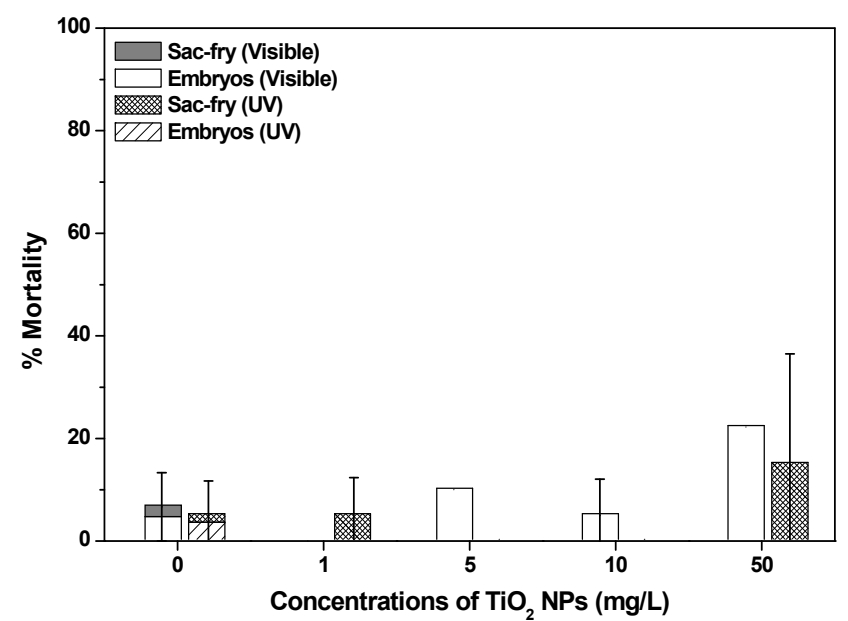

Fig. 5. Cumulative mortality of $\mathrm{TiO}_{2} \mathrm{NPs}$ under visible light or UV irradiation on Oryzias latipes.

zebrafish embryos and larvae. They reported that $10 \mathrm{mg} / \mathrm{L}$ uncoated $\mathrm{TiO}_{2}$ NPs induced hydroxyl radicals, production of lipid peroxidation, and increase of total glutathione level under UV illumination, unlike poly (acrylic acid)-coated $\mathrm{TiO}_{2} \mathrm{NPs}$, due to surface coating. It has been suggested that phototoxicity is due to the production of reaction oxygen species (ROS) that are generated by the exposure of $\mathrm{TiO}_{2} \mathrm{NPs}$ to UV light and damage the receptors [4, 7-8, 12]. However, the results showed that lethal phototoxicity occurs only at relatively high exposure concentrations (100-1,000 $\mathrm{mg} / \mathrm{L})$.

\section{Conclusions}

This study showed that $\mathrm{TiO}_{2}$ NPs under UV or visible light cause abnormalities to $O$. latipes embryos and sac-fry at tested concentrations (10 and $50 \mathrm{mg} / \mathrm{L}$ ), while the mortality of $\mathrm{TiO}_{2} \mathrm{NP}$-treated sac-fry was not significant under UV or visible light. Additionally, no significant differences were identified under UV or visible light at the same low exposure concentrations $(0-50 \mathrm{mg} / \mathrm{L})$ of bare $\mathrm{TiO}_{2}$ NPs. Therefore, further research is needed to assess the effects of higher exposure concentrations of $\mathrm{TiO}_{2} \mathrm{NPs}$ than those tested in this study and the effects of different surface coating of nanoparticles. Further research is also needed to evaluate the toxicity of NPs in natural surface waters for investigating their potential photo-activation and risk involved in biotic partitioning of NPs.

\section{Acknowledgments}

This research was supported by Basic Science Research Program through the National Research Foundation of Korea (NRF) funded by the Ministry of Science, ICT and Future Planning (2016R1A2B3010445). This work was supported by Korea Environment Industry \& Technology Institute (KEITI) through "The Chemical Accident Prevention Technology Development Project", funded by Korea Ministry of Environment(MOE) (No. 2016001970001). The authors thank the Korean Basic Science Institute (KBSI) for FE-TEM, particle size analyzer, and ELS analyses.

\section{References}

1. Clemente Z, Castro VLSS, Moura MAM, Jonsson CM, Fraceto LF. Toxicity assessment of $\mathrm{TiO}_{2}$ nanoparticles in zebrafish embryos under different exposure conditions. Aquat. Toxicol. 2014;147:129-139.

2. Boxall A, Chaudhry Q, Sinclair C, et al. Current and future predicted environmental exposure to engineered nanoparticles. Central Science Laboratory; 2007.

3. Wang $\mathrm{H}$, Wick RL, Xing B. Toxicity of nanoparticulate and bulk $\mathrm{ZnO}, \mathrm{Al}_{2} \mathrm{O}_{3}$ and $\mathrm{TiO}_{2}$ to the nematode Caenorhabditis elegans. Environ. Pollut. 2009;157:1171-1177.

4. Bar-Ilan O, Louis KM, Yang SP, et al. Titanium dioxide nanoparticles produce phototoxicity in the developing zebrafish. Nanotoxicology 2012;6:670-679.

5. Faria M, Navas JM, Soares AMVM, Barata C. Oxidative stress effects of titanium dioxide nanoparticle aggregates in zebrafish embryos. Sci. Total Environ. 2014;470-471:379-389.

6. Clemente Z, Castro VL, Feitosa LO, et al. Fish exposure to nano- $\mathrm{TiO}_{2}$ under different experimental conditions methodological aspects for nanoecotoxicology investigations. Sci. Total Environ. 2013;463-464:647-656.

7. Li S, Pan X, Wallis LK, Fan Z, Chen Z, Diamond SA. Comparison of $\mathrm{TiO}_{2}$ nanoparticle and graphene- $\mathrm{TiO}_{2}$ nanoparticle composite phototoxicity to Daphnia magna and Oryzias latipes. Chemosphere 2014;112:62-69.

8. Ma H, Brennan A, Diamond SA. Photocatalytic reactive oxygen species production and phototoxicity of titanium dioxide nanoparticles are dependent on the solar ultraviolet radiation spectrum. Environ. Toxicol. Chem. 2012a;31:2099-2107.

9. Ma H, Brennan A, Diamond SA. Phototoxicity of $\mathrm{TiO}_{2}$ nanoparticles under solar radiation to two aquatic species: Daphnia magna and Japanese medaka. Environ. Toxicol. Chem. 2012b;31:1621-1629.

10. Shin YJ, Nam SH, An YJ. Continuous UV irradiation increases the adverse effects of photoreactive nanoparticles on the early development of Oryzias latipes. Environ. Toxicol. Chem. 2015;35:1195-1200.

11. Lindsey CF, Erik JF, Yuhe H, Greg GG. Poly(acrylic acid)-coated titanium dioxide nanoparticle and ultraviolet light co-exposure has minimal effect on developing zebrafish (Danio rerio). Environ. Sci. Nano. 2017;4:658-669.

12. Lee WM, An YJ. Effects of zinc oxide and titanium dioxide nanoparticles on green algae under visible, UVA, and UVB irradiations: No evidence of enhanced algal toxicity under UV pre-irradiation. Chemosphere 2013;91:536-544.

13. Kim SW, An YJ. Effect of $\mathrm{ZnO}$ and $\mathrm{TiO}_{2}$ nanoparticles preilluminated with UVA and UVB light on Escherichia coli and Bacillus subtilis. Appl. Microbiol. Biotechnol. 2012;95:243-253.

14. Ma H, Diamond SA, Phototoxicity of $\mathrm{TiO}_{2}$ nanoparticles to zebrafish (Danio rerio) is dependent on life stage. Environ. Toxicol. Chem. 2013;32:2139-2143. 
15. Shin YJ, Nam SH, An YJ. Japanese medaka exposed to gold nanoparticles: Only embryonic exposure generates irreversible hatching failure, developmental failure, and mortality of sac-fry. Comp. Biochem. Phys. C. 2014;161:26-32.

16. Truong L, Saili KS, Miller JM, Hutchison JE, Tanguay RL. Persistent adult zebrafish behavioral deficits results from acute embryonic exposure to gold nanoparticles. Comp. Biochem. Phys. C. 2012;155:269-274

17. Organization for Economic Co-operation and Development
(OECD). Guideline for testing of chemicals no. 212. Fish, short-term toxicity test on embryo and sac-fry stages. 1998.

18. Kirchen RV, West WR. The Japanese medaka: Its care and development [Ichthyology; Fishes]. Burlington, North Carolina: Carolina Biological Supply Co.; 1976.

19. Shen W, Li Z, Wang H, Liu Y, Guo Q, Zhang Y. Photocatalytic degradation for methylene blue using zinc oxide prepared by codeposition and sol-gel methods. J. Hazard. Mater. 2008;152:172-175. 